\title{
NGHIÊN CÚU SỰ THAY ĐỔI Độ CAO GIŨ̃A MặT QUASIGEOID CỤC Bộ HÒN DẤU VÀ MậT QUASIGEOID TOÀN CẦU TRÊN PHẠM VI TOÀN CÂUU
}

PGS. TSKH. HÀ MINH HOÀ

Viện Khoa học Đo đạc và Bản đồ

\section{Tóm tắt:}

Bài báo khoa học này đã chứng minh sự không đổi của độ cao của điểm bất kỳ trên mặt quasigeoid cục bộ Hòn Dấu so với mặt quasigeoid toàn cầu trên phạm vi toàn cầu. Đây là cơ' sở khoa học rất quan trọng để khai thác các mô hình trọng trường Trái đất EGM và mô hình địa hình động lực trung bình MDT (Mean Dynamic Topography) quốc tế trong việc giải quyết các bài toán trắc địa vật lý trên lãnh thổ quốc gia hoặc khu vực.

\section{1. Đặt vấn đề}

Trong các tài liệu (Hà Minh Hòa. (2010); Hà Minh Hòa (2013); Hà Minh Hòa. (2014)) khi đưa ra định nghĩa về mặt quasigeoid, theo đó mặt quasigeoid là hình ảnh của mặt geoid trong trọng trường chuẩn của ellipsoid nhận được từ phép chiếu mặt geoid theo phương vuông góc với mặt ellipsoid vào trong trọng trường chuẩn của ellipsoid.

Do mặt quasigeoid trùng với mặt geoid với thế trọng trường thực $W_{0}$ trên biển và các đại dương và càng vào sâu trong đất liền càng tách dần khỏi mặt geoid, nên từ điểm $\mathrm{M}$ trên mặt vật lý Trái đất dựng đường $M Q_{0}$ vuông góc với mặt ellipsoid, đường $M Q_{0}$ cắt mặt quasigeoid tại điểm $\mathrm{Q}(x e m$ hình 1). Các tài liệu (Hà Minh Hòa. (2010); Hà Minh Hòa (2013); Hà Minh Hòa. (2014)) đã chứng minh được rằng thế trọng trường chuẩn $U_{Q}$ tại điểm $Q$ trên mặt quasigeoid quan hệ với thế trọng trường $W_{0}$ của mặt geoid theo công thức:

$$
U_{Q}=W_{0}-T_{M}
$$

ở đây $T_{M}=W_{M}-U_{M}$ là thế nhiễu, còn $W_{M}$ là thế trọng trường thực, $U_{M}$ là thế trọng trường chuẩn tại điểm $\mathrm{M}$.
Như vậy, sự tồn tại thế nhiễu $T_{M}$ khác 0 tại điểm $M$ do sự khác nhau của trọng trường thực của Trái đất và trọng trường chuẩn của ellipsoid gây ra sự khác nhau giữa thế trọng trường chuẩn $U_{Q}$ tại điểm $Q$ trên mặt quasigeoid và thế trọng trường thực $W_{0}$ của mặt geoid. Trên biển và các đại dương thế giới, mặt geoid sát nhất, nhưng không trùng với mặt biển trung bình nhiều năm. Mặt biển trung bình nhiều năm còn được gọi là mặt địa hình biển chênh với mặt geoid toàn cầu ở mức $\pm 2 \mathrm{~m}$ (Pellinen L.P. (1978); Rapp R.H, Balasubramania N. (1992)). Trên biển và các đại dương thế giới, mặt quasigeoid trùng với mặt geoid, tức mặt quasigeoid là mặt đẳng thế thực trên biển và các đại dương, nhưng từ công thức (1) chúng ta thấy rằng các thế trọng trường chuẩn của các điểm $Q$ nằm trên mặt quasigeoid (đồng thời là trên mặt geoid) không bằng nhau do sự tồn tại các thế nhiễu khác 0 của các điểm $\mathrm{M}$ nằm trên mặt địa hình biển. Trong lục địa, các thế trọng trường chuẩn của các điểm $Q$ nằm trên mặt quasigeoid cũng không bằng nhau do sự tồn tại các thế nhiễu khác 0 của các điểm $\mathrm{M}$ nằm trên bề mặt địa hình lục địa. Như vậy mặt quasigeoid không phải là mặt đẳng thế chuẩn trong trọng trường chuẩn của ellipsoid. (xem hinh 2) 


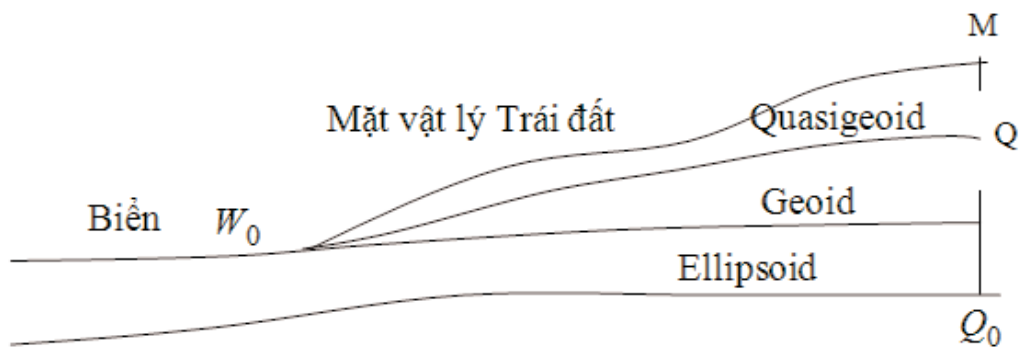

Hình 1: Quan hệ giữa mặt geoid và quasigeoid

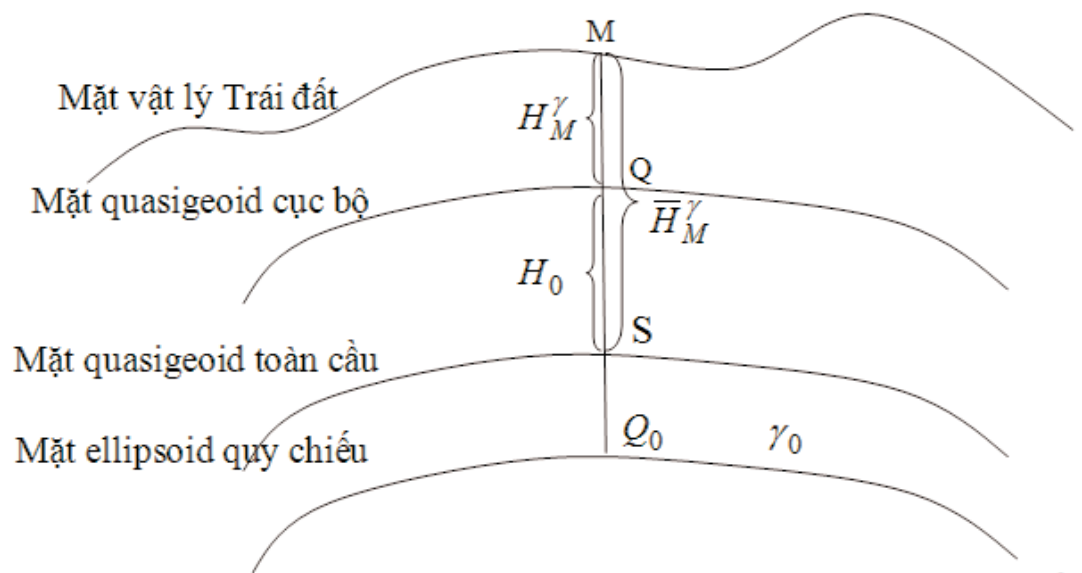

Hình 2: Quan hệ giữa mặt quasigeoid cục bộ và mặt quasigeoid toàn cầu

Chúng ta gọi mặt geoid cục bộ với thế trọng trường thực $W_{O}$ là mặt đẳng thế sát nhất với mặt biển trung bình nhiều năm tại trạm nghiệm triều 0 (ở Việt Nam là trạm nghiệm triều Hòn Dấu). Khi đó mặt quasigeoid cục bộ là mặt trùng với mặt geoid cục bộ trên các biển và các đại dương thế giới. Trong các tài liệu (Hà Minh Hòa và nnk. (2012); Hà Minh Hòa (2013); Hà Minh Hòa. (2014 ); Hà Minh Hòa, Nguyễn Thị Thanh Hương, Lương Thanh Thạch (2015)) đã công bố các kết quả tính toán và kiểm tra thế trọng trọng trường $W_{0}$ của mặt geoid cục bộ Hòn Dấu, theo đó $W_{0}=$ $62636847.2911 \mathrm{~m}^{2} . \mathrm{s}^{-2}$.

Mặt geoid toàn cầu với thế trọng trường thực $\bar{W}_{0}$ là mặt đẳng thế sát nhất với mặt biển trung bình nhiều năm trên các biển và các đại dương thế giới. Hiện nay giá trị thế trọng trường $\bar{W}_{0}=62636847.2911 \mathrm{~m}^{2} \cdot \mathrm{s}^{-2}$ của mặt geoid toàn cầu được xác định từ các dữ liệu altimetry và được tổ chức Dịch vụ quay Trái đất (IERS) công bố trong các tài liệu (Dennis D. McCarthy, Gerard Petit. (2004); Petit G., Luzum B. (2010)). Giá trị thế trọng trường này được sử dụng để xác định bán kính bán trục lớn của ellipsoid Trái đất trung bình TFS2008 (Tide-Free Sysem 2008) phục vụ việc xây dựng mô hình trọng trường Trái đất EGM2008 (xem các tài liệu Pavlis Nikolas K, Simon A. Holmes, Steve C. Kenyon, John K. Factor (2008); Tenzer R., Vatrt V. and Amos M. (2009)).

Tương ứng với mặt geoid cục bộ Hòn Dấu và mặt geoid toàn cầu là mặt quasigeoid cục bộ Hòn Dấu và mặt quasigeoid toàn cầu (xem hình 2). Từ điểm $\mathrm{M}$ trên mặt vật lý Trái đất dựng đường $M Q_{0}$ vuông góc với mặt ellipsoid. Đường $\mathrm{MQ}_{0}$ cắt quasigeoid cục bộ tại điểm $Q$ với thế trọng trường 
chuẩn $U_{Q}$ và cắt mặt quasigeoid toàn cầu tại điểm $S$ với thế trọng trường chuẩn $U_{S}$ Từ công thức (1) chúng ta có các quan hệ:

$$
\begin{aligned}
& U_{Q}=W_{0}-T_{M} \\
& U_{S}=\bar{W}_{0}-T_{M}
\end{aligned}
$$

và từ đây suy ra quan hệ:

$$
\bar{W}_{0}-W_{0}=U_{S}-U_{Q}
$$

Từ quan hệ trên chúng ta xác định được độ cao $\mathrm{H}_{0}$ của mặt quasigeoid cục bộ Hòn Dấu so với mặt quasigeoid toàn cầu dưới dạng sau: ${ }_{H_{0}}=\frac{U_{S}-U_{Q}}{\bar{\gamma}_{M}}=\frac{\bar{W}_{0}-W_{0}}{\bar{\gamma}_{M}}=\frac{8.7089 \mathrm{~m}^{2} . \mathrm{s}^{-2}}{\bar{\gamma}_{M}}$

ở đây giá trị trung bình của gia tốc lực trọng trường chuẩn $\bar{\gamma}_{M}$ trong công thức (2) có đơn vị $m \cdot s^{-2}$ và được tính toán theo công thức:

$$
\begin{aligned}
& \bar{\gamma}_{M}=\gamma_{0}-0.000001543\left(s^{-2}\right) H_{M}^{\gamma}+ \\
& 0.036 * 10^{-11}\left(\frac{s^{-2}}{m}\right)\left(H_{M}^{\gamma}\right)^{2}<m s^{-2}>,
\end{aligned}
$$

ở đây gia tốc lực trọng trường chuẩn $\gamma_{0}$ trên mặt ellipsoid quy chiếu quốc tế WGS84 được xác định theo công thức:

$$
\begin{aligned}
& \gamma_{0}=9.7803253359\left(1+0.00530248 \sin ^{2} B\right. \\
& \left.\left.-0.0000058497 \sin ^{2} 2 B\right)<m \cdot s^{-2}\right\rangle
\end{aligned}
$$

Trong các tài liệu (Hà Minh Hòa. (2010); Hà Minh Hòa (2013); Hà Minh Hòa. (2014)) dựa trên 11 điểm trọng lực cơ sở và 29 điểm trọng lực hạng I phủ trùm toàn bộ lãnh thổ Việt Nam từ khu vực núi cao đến một số đảo thuộc biển Đông đã xác định độ cao $\mathrm{H}_{0}=$ $0.890 \mathrm{~m}$ và là đại lượng không đổi trên toàn bộ lãnh thổ Việt Nam. Trong tài liệu (Nguyễn Tuấn Anh (2015)) đã kiểm tra và xác nhận sự đúng đắn của kết luận dựa trên 133 điểm trọng lực chi tiết được phân bố trên 09 vùng Tây Bắc, Đông Bắc, Tây Tây Bắc, Đông Đông Bắc, Bắc Trung Bộ, Trung Bộ, Nam Trung Bộ, Tây Nguyên, Nam Bộ thuộc lãnh thổ Việt Nam.

Như vậy, độ cao $\mathrm{H}_{0}$ của mặt quasigeoid cục bộ Hòn Dấu so với mặt quasigeoid toàn cầu luôn bằng $0.890 \mathrm{~m}$ và không đổi trên lãnh thổ Việt Nam. Đây là tính chất rất quan trọng của mối quan hệ giữa mặt quasigeoid cục bộ và quasigeoid toàn cầu và là cơ sở khoa học để khai thác các mô hình trọng trường Trái đất EGM và mô hình địa hình động lực trung bình MDT (Mean Dynamic Topography) quốc tế trong việc giải quyết các bài toán trắc địa vật lý trên lãnh thổ quốc gia.

Tuy nhiên đến đây nẩy sinh câu hỏi: Độ cao $\mathrm{H}_{0}=0.890 \mathrm{~m}$ của mặt quasigeoid cục bộ Hòn Dấu so với mặt quasigeoid toàn cầu có còn luôn không đổi trên phạm vi toàn cầu hay không? Việc trả lời câu hỏi này sẽ xác lập cơ sở khoa học cho việc giải quyết hàng loạt vấn đề liên quan đến việc thống nhất hệ độ cao khu vực và toàn cầu, xây dựng mô hình quasigeoid khu vực .v.v... Việc trả lời câu hỏi nêu trên là nội dung của bài báo khoa học này.

\section{Giải quyết vấn đề}

Trước tiên chúng ta phải thống nhất rằng mặt geoid cục bộ Hòn Dấu và mặt geoid toàn cầu là hai mặt đẳng thế thực trong trọng trường thực của Trái đất và chúng không song song với nhau trên phạm vi toàn cầu. Theo các tài liệu (Balasubramania N. (1994); Véronneau M. (2006)), sự không song song với nhau của hai mặt đẳng thế trọng trường thực gần bề mặt Trái đất là do sự không đồng đều của trọng trường Trái đất, sự phân bố vật chất không đồng đều trong lòng Trái đất và sự quay không đồng đều của Trái đất. Các mặt đẳng thế thực hội tụ sát vào nhau ở các cực Trái đất mà ở đó gia tốc lực trọng trường lớn hơn so với ở xích đạo Trái đất. Do đó khoảng cách giữa hai mặt đẳng thế ngắn hơn ở các cực Trái đất và dài hơn ở gần xích đạo Trái đất. 
Tuy nhiên, như đã trình bày ở trên, mặt quasigeoid cục bộ Hòn Dấu và mặt quasigeoid toàn cầu được xác định trong trọng trường chuẩn của ellipsoid quy chiếu theo lý thuyết Molodenxkii M.X., nhưng không phải là các mặt đẳng thế và sự không đổi của độ cao $\mathrm{H}_{0}$ của mọi điểm nằm trên mặt quasigeoid cục bộ Hòn Dấu so với mặt quasigeoid toàn cầu hoàn toàn có thể được giải thích do trọng trường chuẩn (trọng trường lý thuyết) đồng đều và đối xứng, tốc độ quay của ellipsoid luôn không đổi, mật độ vật chất của ellipsoid là đồng nhất, giá trị trung bình của gia tốc lực trọng trường thay đổi theo quy luật phụ thuộc vào vĩ độ và độ cao của các điểm trên mặt vật lý Trái đất. Bởi vì mặt quasigeoid được xác định trong trọng trường chuẩn của ellipsoid quy chiếu, nên các chênh cao đo hạng I, II quốc gia luôn được tính chuyển từ trọng trường thực của Trái đất về trọng trường chuẩn của ellipsoid quy chiếu.

Như vậy, mặc dù các khoảng cách giữa mặt geoid cục bộ Hòn Dấu và mặt geoid toàn cầu không bằng nhau trên phạm vi toàn cầu, nhưng khoảng cách giữa các hình ảnh của chúng - giữa mặt quasigeoid cục bộ và quasigeoid toàn cầu trong trọng trường chuẩn của ellipsoid hoàn toàn có thể không đổi trên phạm vi toàn cầu. Chúng ta sẽ chứng minh điều này.

Để chứng minh sự không đổi của độ cao $\mathrm{H}_{0}$ theo công thức (2), chúng ta thấy rằng trong công thức này tử số là đại lượng không đổi và sự thay đổi của độ cao $\mathrm{H}_{0}$ chỉ phụ thuộc vào sự thay đổi của giá trị trung bình $\bar{\gamma}_{M}$ của gia tốc lực trọng trường chuẩn ở mẫu số. Về phần mình, từ các công thức (3), (4) chúng ta thấy rằng giá trị trung bình $\bar{\gamma}_{M}$ của gia tốc lực trọng trường chuẩn chỉ phụ thuộc vào vĩ độ trắc địa $\mathrm{B}$ và độ cao chuẩn $H_{M}^{\gamma}$ của điểm $\mathrm{M}$ trên mặt vật lý Trái đất. Ngoài ra, khi giá trị trung bình $\bar{\gamma}_{M}$ của gia tốc lực trọng trường chuẩn được biểu diễn trong đơn vị $m . s^{-2}$, ngay cả với độ cao của đỉnh Everest $H^{\gamma}=8848 \mathrm{~m}$ thành phần với $\left(H_{M}^{\gamma}\right)^{2}$ cũng chỉ ở mức $0.00003 \mathrm{~m} . \mathrm{s}^{-2}$ và nhỏ bỏ qua. Khi đó công thức (3) có dạng:

$$
\begin{aligned}
\bar{\gamma}_{M}= & \gamma_{0}-0.000001543 H_{M}^{\gamma}= \\
& \gamma_{0} \cdot\left(1-\frac{0.000001543 H_{M}^{\gamma}}{\gamma_{0}}\right)<m \cdot s^{-2}>.
\end{aligned}
$$

Thay biểu thức trên vào (2) chúng ta có:

$$
\begin{aligned}
& H_{0}=\frac{8.7089 \mathrm{~m}^{2} \cdot \mathrm{s}^{-2}}{\gamma_{0}} \cdot\left(1-\frac{0.000001543 H_{M}^{\gamma}}{\gamma_{0}}\right)^{-1}= \\
& \frac{8.7089 \mathrm{~m}^{2} \cdot \mathrm{s}^{-2}}{\gamma_{0}}+\frac{0.0000134378327 H_{M}^{\gamma}}{\gamma_{0}^{2}}=A+B, \\
& \text { Ở đây } A=\frac{8.7089 \mathrm{~m}^{2} \cdot \mathrm{s}^{-2}}{\gamma_{0}}, \\
& B=\frac{0.0000134378327 H_{M}^{\gamma}}{\gamma_{0}^{2}}
\end{aligned}
$$

Do sự thay đổi của độ cao $\mathrm{H}_{0}$ (2) chỉ phụ thuộc vào vĩ độ trắc địa $\mathrm{B}$ và độ cao chuẩn $H_{M}^{\gamma}$ của điểm $\mathrm{M}$ trên mặt vật lý Trái đất, nên chúng ta xem xét trường hợp tồi nhất với giả thiết rằng bề mặt vật lý Trái đất từ xích đạo đến cực Trái đất được coi là có độ cao bằng độ cao của đỉnh Everest và bằng $8848 \mathrm{~m}$. Chúng ta tính toán đại lượng $\mathrm{H}_{0}$ ở trên xích đạo $\left(B=0^{\circ}\right)$, trên vĩ tuyến với vĩ độ $B=45^{\circ}$ và trên cực Trái đất $\left(B=90^{\circ}\right)$. Các kết quả tính toán được trình bày trong bảng 1 ở dưới đây. (xem bảng 1)

Các kết quả tính toán ở bảng 1 đối với trường hợp tồi nhất, khi bề mặt vật lý Trái đất từ xích đạo đến cực Trái đất được coi là có độ cao bằng độ cao của đỉnh Everest và bằng $8848 \mathrm{~m}$, cho kết luận sau:

Độ cao $H_{0}$ giữa mặt quasigeoid cục bộ Hòn Dấu và mặt quasigeoid toàn cầu được nhận bằng $0.890 \mathrm{~m}$ và là đại lượng không đổi trên phạm vi toàn cầu. 
Bảng 1

\begin{tabular}{|c|c|c|c|c|}
\hline Vĩ độ trắc địa B & Gia tốc lực trọng trường chuẩn $\gamma_{0}\left(m s^{-2}\right)$ & $\mathrm{A}(\mathrm{m})$ & $\mathrm{H}(\mathrm{m})$ & $H_{0}$ \\
\hline $0^{\circ}$ & 9.7803253359 & 0.890 & 0.001 & 0.891 \\
\hline $45^{\circ}$ & 9.8061981137 & 0.888 & 0.001 & 0.889 \\
\hline $90^{\circ}$ & 9.8321849379 & 0.886 & 0.001 & 0.887 \\
\hline
\end{tabular}

Với mục đích kiểm tra sự đúng đắn của kết luận nêu trên trên phạm vi toàn cầu, chúng ta tiến hành tính toán trên một số khu vực có các đỉnh núi cao nhất như đỉnh Fansipan ở Việt Nam, đỉnh Everest thuộc dãy Himalaya ở Nepal, đỉnh Nanda Devi ở Ân Độ, đỉnh Nanga Parbat ở Pakistan, đỉnh Elbrus thuộc khu vực Kavkaz (Liên bang Nga) và đỉnh Blanc thuộc dãy Alp trên lãnh thổ Pháp và Italia, đỉnh Denali (McKinley) ở Alaska (Mỹ), đỉnh Kilimanjaro ở Tanzania và đỉnh Aconcagua ở Chi Lê. Các kết quả tính toán được trình bày trong bảng (xem bảng 2) đã xác nhận sự đúng đắn của kết luận trên.

Chúng ta có thể kiểm tra sự đúng đắn của kết luận nêu trên theo một cách khác. Trong các tài liệu (Hà Minh Hòa. (2010); Hà Minh Hòa (2013); Hà Minh Hòa. (2014)) đã chứng minh quan hệ giữa độ cao chuẩn cục bộ $H_{M}^{\gamma}$ và độ cao chuẩn toàn cầu $\bar{H}_{M}^{\gamma}$ của điểm $\mathrm{M}$ bất kỳ trên mặt vật lý Trái đất (xem hình 2) ở dạng sau:

$$
\bar{H}_{M}^{\gamma}=H_{M}^{\gamma}+\frac{\bar{W}_{0}-W_{0}}{\bar{\gamma}_{M}} .
$$

Giả sử với hai điểm, bất kỳ 1 và 2 nằm trên bê mặt vật lý Trái đất, từ công thức trên chúng ta có các quan hệ:

$$
\begin{aligned}
& \bar{H}_{1}^{\gamma}=H_{1}^{\gamma}+\frac{\bar{W}_{0}-W_{0}}{\bar{\gamma}_{1}}, \\
& \bar{H}_{2}^{\gamma}=H_{2}^{\gamma}+\frac{\bar{W}_{0}-W_{0}}{\bar{\gamma}_{2}}
\end{aligned}
$$

và từ đây suy ra công thức:

$$
\begin{aligned}
& \bar{H}_{2}^{\gamma}-\bar{H}_{1}^{\gamma}=H_{2}^{\gamma}-H_{1}^{\gamma}+\left(\bar{W}_{0}-W_{0}\right)\left[\frac{1}{\bar{\gamma}_{2}}-\frac{1}{\bar{\gamma}_{1}}\right]= \\
& =H_{2}^{\gamma}-H_{1}^{\gamma}+8.7089 \mathrm{~m}^{2} \cdot \mathrm{s}^{-2}\left[\frac{1}{\bar{\gamma}_{2}}-\frac{1}{\bar{\gamma}_{1}}\right] .
\end{aligned}
$$

Từ bảng 2, khi chọn điểm 1 là đỉnh Aconcagua (Chi Lê) ở Nam bán cầu và điểm 2 là đỉnh Denali (Bắc Mỹ) ở Bắc bán cầu, chúng ta có:

$$
\begin{aligned}
& 8.7089 \mathrm{~m}^{2} \cdot \mathrm{s}^{-2}\left[\frac{1}{\bar{\gamma}_{2}}-\frac{1}{\bar{\gamma}_{1}}\right]= \\
& 8.7089 \mathrm{~m}^{2} \cdot \mathrm{s}^{-2}\left[\frac{1}{9.81199}-\frac{1}{9.78464}\right]=-10002, \mathrm{w}
\end{aligned}
$$
là đại lượng nhỏ bỏ qua trong Trắc địa vật lý. Việc chọn các điểm 1 và 2 bất kỳ từ bảng 2 cũng cho kết quả tương tự.

Như vậy, từ (5) chúng ta luôn nhận được đẳng thức: $\quad \bar{H}_{2}^{\gamma}-\bar{H}_{1}^{\gamma}=H_{2}^{\gamma}-H_{1}^{\gamma}$

Từ đây chúng ta thây răng độ cao $H_{0}$ của mặt quasigeoid cục bộ Hòn Dấu so với mặt quasigeoid toàn cầu tương ứng với mọi điểm bất kỳ trên mặt vật lý Trái đất đều là đại lượng không đổi ở dạng sau:

$$
H_{0}=\bar{H}_{1}^{\gamma}-H_{1}^{\gamma}=\bar{H}_{2}^{\gamma}-H_{2}^{\gamma}=\text { const }
$$

\section{Kết luận}

Các kết quả nghiên cứu trong bài báo khoa học này cho thấy rằng trong trọng trường chuẩn của ellipsoid quy chiếu, độ cao của điểm bất kỳ nằm trên mặt quasigeoid cục bộ so với mặt quasigeoid toàn cầu luôn là đại lượng không đổi. Đối với mặt quasigeoid cục bộ Hòn dấu, độ cao của điểm bất kỳ nằm trên nó so với mặt quasigeoid toàn cầu luôn bằng $0.890 \mathrm{~m}$. Tính chất này là cơ sở khoa học để khai thác các mô hình trọng trường Trái đất $\mathrm{EGM}$ và mô hình địa hình động lực trung bình MDT 
Bảng 2

\begin{tabular}{|c|c|c|c|c|c|}
\hline Các đỉnh núi & $\begin{array}{l}\text { Các tọa độ } \\
\text { trắc địa } B \text { và } \\
\text { L }\end{array}$ & $\begin{array}{l}\text { Độ cao } \\
\xi^{\prime \prime}(\mathrm{m})\end{array}$ & 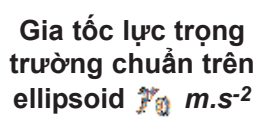 & $\begin{array}{c}\text { Giá trị trung bình của gia tốc } \\
\text { lực trọng trường chuẩn trên } \\
\text { ellipsoid } \mathrm{m}^{-\mathrm{s}^{-2}}\end{array}$ & Độ cao $H_{0}(\mathrm{~m})$ \\
\hline $\begin{array}{c}\text { Fansipan } \\
\text { (Việt Nam) }\end{array}$ & $\begin{array}{c}2^{\circ} 17^{\prime} 52^{\prime \prime} \mathrm{N} \\
103^{\circ} 47^{\prime} 11^{\prime \prime}\end{array}$ & 3143 & 9.78654 & 9.78172 & 0.890 \\
\hline $\begin{array}{l}\text { Everest } \\
\text { (Nepal) }\end{array}$ & $\begin{array}{l}27^{0} 59^{\prime} 14^{\prime \prime} \mathrm{N} \\
86^{\circ} 55^{\prime} 31 \text { 'E }\end{array}$ & 8848 & 9.79171 & 9.77806 & 0.891 \\
\hline \begin{tabular}{|c|} 
Nanda Devi \\
(Ấn Độ)
\end{tabular} & $\begin{array}{l}30^{\circ} 22^{\prime} 36 \text { "N } \\
79^{\circ} 58^{\prime} 15^{\prime \prime} \mathrm{E}\end{array}$ & 7816 & 9.79354 & 9.78148 & 0.890 \\
\hline $\begin{array}{c}\text { Nanga } \\
\text { Parbat } \\
\text { (Pakistan) }\end{array}$ & $\begin{array}{l}35^{\circ} 14^{\prime} 18^{\prime \prime} \mathrm{N} \\
74^{\circ} 35^{\prime} 22^{\prime \prime} \mathrm{E}\end{array}$ & 8125 & 9.79754 & 9.78500 & 0.890 \\
\hline $\begin{array}{l}\text { Elbrus } \\
\text { (Kavkaz) } \\
\text { (Nga) }\end{array}$ & $\begin{array}{c}\mathrm{F} 43^{\circ} 21^{\prime} 18^{\prime \prime} \mathrm{N} \\
42^{\circ} 26^{\prime} 21^{\prime \prime} \mathrm{E}\end{array}$ & 5642 & 9.80471 & 9.79600 & 0.889 \\
\hline \begin{tabular}{c|} 
Blanc (Alp) \\
(Pháp - Italia)
\end{tabular} & $\begin{array}{l}45^{\circ} 50^{\prime} 01^{\prime \prime} \mathrm{N} \\
06^{\circ} 51^{\prime} 54^{\prime \prime} \mathrm{E}\end{array}$ & 4810 & 9.80695 & 9.79953 & 0.889 \\
\hline \begin{tabular}{|c|} 
Denali \\
(McKinley) \\
(Alaska, Mỹ)
\end{tabular} & $\begin{array}{c}63^{\circ} 04^{\prime} 10^{\prime \prime} \mathrm{N} \\
151^{\circ} 00^{\prime} 27^{\prime \prime} \mathrm{W}\end{array}$ & 6468 & 9.82151 & 9.81199 & 0.888 \\
\hline \begin{tabular}{|c|} 
Kilimanjaro \\
(Tanzania)
\end{tabular} & $\begin{array}{l}03^{\circ} 04^{\prime} 33^{\prime \prime} \mathrm{S} \\
37^{0} 21^{\prime} 12 \text { "E }\end{array}$ & 5898.7 & 9.780474 & 9.77137 & 0.891 \\
\hline \begin{tabular}{|c|}
$\begin{array}{c}\text { Puncak Java } \\
\text { (Indonexia) }\end{array}$ \\
\end{tabular} & $\begin{array}{c}04^{\circ} 04^{\prime} 44^{\prime \prime} \mathrm{S} \\
137^{\circ} 09^{\prime} 30^{\prime \prime} \mathrm{E}\end{array}$ & 4884 & 9.78059 & 9.77305 & 0.891 \\
\hline $\begin{array}{c}\text { Aconcagua } \\
\text { (Chi Lê) }\end{array}$ & $\begin{array}{l}32^{\circ} 39^{\prime} 12^{\prime \prime} \mathrm{S} \\
70^{\circ} 00^{\prime} 40^{\prime \prime} \mathrm{W}\end{array}$ & 6959 & 9.79538 & 9.78464 & 0.890 \\
\hline
\end{tabular}

(Mean Dynamic Topography) quốc tế trong việc giải quyết các bài toán trắc địa vật lý trên lãnh thổ quốc gia hoặc khu vực. $\bigcirc$

\section{Tài liệu tham khảo}

[1]. Balasubramania N. (1994). Definition and Realization of a global vertical datum. Scientific Report No 1, AD-A283303, PLTR-94-2144, the Ohio State University, Department of Geodetic Science and Surveying, Columbus, $122 \mathrm{p}$.

[2]. Dennis D. McCarthy, Gerard Petit. (2004). IERS Conventions (2003). IERS Technical Note No 32. Frankfurt am Main, 2004.

[3]. Hà Minh Hòa. (2010). Tiếp cận khái niệm về mặt Quasigeoid. Tạp chí Khoa học Đo đạc và Bản đồ, No3, 3/2010, trg. 3 - 15.

[4]. Hà Minh Hòa và nnk (2012). Nghiên cứu cơ sở khoa học của việc hoàn thiện hệ độ cao gắn liền với việc xây dựng hệ tọa độ động lực quốc gia. Đề tài khoa học và công nghệ cấp Bộ Tài nguyên và Môi trường giai đoạn 2010 - 2012. Hà Nội - 2012.

[5]. Ha Minh Hoa (2013). Estimating the geopotential value WO of the local geoid based on data from local and global normal heights of GPS/Leveling points in Vietnam. Geodesy and Cartography. Taylor \& Francis. UDK 528.21, doi:10.3846/20296991.2013.823705, V.39 (3): 99-105. 
[6]. Hà Minh Hòa (2014). Lý thuyết và thực tiễn của Trọng lực trắc địa. Nhà Xuất bản Khoa học và Kỹ thuật, 592 trg. Hà Nội 2014.

[7]. Hà Minh Hòa, Nguyễn Thị Thanh Hương, Lương Thanh Thạch (2015), Đánh giá kiểm tra thế trọng trường WO của mặt geoid cục bộ Hòn Dấu trên cơ sở sử dụng 89 điểm độ cao hạng I. Tạp chí Khoa học Đo đạc và Bản đồ, số 26, tháng 12/2015, trg. 1 $-15$.

[8]. Nguyễn Tuấn Anh (2015). Nghiên cứu chi tiết độ cao của mặt geoid cục bộ Hòn Dấu so với mặt geoid toàn cầu trên lãnh thổ Việt Nam. Tạp chí Khoa học Đo đạc và Bản đồ, No25, 09/2015.

[9]. Pavlis Nikolas K, Simon A. Holmes, Steve C. Kenyon, John K. Factor (2008). An Earth gravitational model to degree 2160: EGM2008. EGU General asembly 2008, Vienna, Austria, April 13 - 18, 2008.

[10]. Pellinen L.P. (1978). Trắc địa cao cấp (trắc địa lý thuyết). Matxcơva, Nedra, 264 trg. (Tiếng Nga).

[11]. Petit G., Luzum B. (2010). IERS Conventions (2010). IERS Technical Note No 36, Verlag dés Bundesamts fur Kartographie und Geodasie. Frankfurt am Main 2010, 179 pp

[12]. Rapp R.H, Balasubramania N. (1992). A conceptual formulation of a World height system. Dept. Geod. Sci. Rep. N421. Ohio State University, Columbus, Ohio.

[13]. Tenzer R., Vatrt V. and Amos M. (2009). Realization of the World Height System in New Zealand: Preliminary Study, pp. 343 - 349. Geodesy for Planet Earth, Proceedings of the 2009 IAG Symposium, Buenos Aires, Argentina, 31 August - 4 September 2009.

[14]. Véronneau M. (2006). Demystifying the vertical datum in Canada: A case study in the Mackenzie Delta, 24 p. Email: marcv@nrcan.gc.ca $\bigcirc$

\section{Summary}

\section{Research of constancy of height between the Hon Dau quasigeoid and global quasigeoid on a world scale}

Assoc. Prof. Dr. Sc. Ha Minh Hoa

Vietnam Institute of Geodesy and Cartography

This scientific article proved a constancy of a height of arbitrary point on the Hon Dau quasigeoid over the global quasigeoid on a world scale. That is very important scientific base for exploitation of the Earth Gravitational Model (EGM) and the Mean Dynamic Topography model (MDT) in solving of the tasks of the phisical geodesy on territory of state or region. $O$ 